\title{
Motorized Two-Wheeler Accidents; A leading Cause of Death and Disabilities: Autopsy Based Study in Tertiary Care Hospital
}

\section{Filza Ali', Mushtaq Ahmad ${ }^{2}$, Qurat ul Ain Kamran ${ }^{3}$, Saba Batool ${ }^{4}$, Asif Jamil Ansari ${ }^{5}$, Fariha Tariq ${ }^{6}$, Altaf Pervez Qasim ${ }^{7}$}

Demonstrator Forensic Medicine, CMH institute of Medical Sciences, (CIMS) Multan Pakistan

1 Corresponding Author, Study Designed, Collection / Analysis of data, Preparation of Results

2 Associate Professor \& HOD, Forensic Medicine, Nishtar Medical University, Multan Pakistan

2 Provided guidance $\mathcal{E}$ support in collection / analysis of data

3 Assistant Professor of Forensic Medicine, Nishtar Medical University, Multan Pakistan

3 Provided help $\mathcal{E}$ support in writing the manuscript $\mathcal{E}$ Discussion writing

4 Assistant Professor of Pharmacology, CMH institute of Medical Sciences, (CIMS) Multan Pakistan

4 Study designing, Tabulation of Results, Statistical Analysis

5 Associate Professor \& HOD, Forensic Medicine, CMH institute of Medical Sciences, (CIMS) Multan Pakistan

5 Helped in designing charts / figures, Proof Reading

6 Assistant Professor of Forensic Medicine, Sheikh Zayed Medical College, Rahim Yar Khan Pakistan

6 Data Analysis \& Proof Reading

7 Professor $\mathcal{E}$ HOD of Forensic Medicine, Abwa Medical College, Faisalabad Pakistan

7 Authentication of references, Layout of manuscript, Critical review

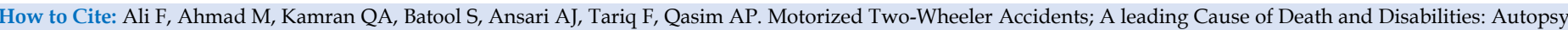
Based Study in Tertiary Care Hospital. APMC 2021;15(1):55-9. DOI: 10.29054/APMC/2021.1019

\section{ABSTRACT}

Background: More than half of all road traffic deaths in the world occur among vulnerable road users including pedestrians, motorcyclists and cyclists whereas; motorcyclists contribute almost one fourth of the death toll of road traffic crashes. Implementation of suitable strategies to address the issues of road traffic crashes is much difficult without information, absolute value of the problem, patterns and risks of injuries \& death. Objective: To determine the different patterns, severity and distribution of injuries \& their frequency in motorized two wheelers accidents. Study Design: Cross-sectional Study. Settings: Study was conducted in the department of Forensic Medicine at Nishtar Medical University, Multan Pakistan. Duration: One year from January 01, 2018 to December 31, 2018. Methodology: Total 167 cases died of road traffic accidents brought for autopsy and of those, 104 cases were reported to be died of motorcycle accidents involving both riders \& pillion riders. The data of victim's age, gender, site and pattern of injuries were obtained through detailed examination of the hospital record, autopsy reports and police inquest. The injuries over head, neck \& thoraco abdominal region were given due consideration being dangerous to life. Statistical analysis was done using SPSS version 20. Results: Of the total 104 cases died in motorcycle accidents; 99 (95.20\%) were males \& 5 (4.80\%) female. Riders died in $81(77.89 \%)$ cases \& pillion riders $23(22.11 \%)$. The age group between 21-40 years involved $67(64.42 \%)$ cases; maximum injuries were observed on Head/Face affecting $84(80.8 \%)$ cases while on thorax $26(25 \%)$ cases, Neck/Spine $12(11.5 \%)$, pelvis $14(13.4 \%)$ and abdominal area sustained injuries in $8(7.6 \%)$ cases. As regard pattern of injuries; abrasions were found in $48(31 \%)$ cases, lacerations $38(24 \%)$, contusions $14(9 \%)$ while fractures were observed in $56(36 \%)$ cases. Among fatal injuries, $74(71 \%)$ were found on Head, 7 (6.7\%) over cervical spines, 3 (2.8\%) on limbs whereas fatal injuries on thorax \& Abdomino-pelvic areas were found $6(9.6 \%)$ in each category. Of the total 81 riders, fractures of skull were observed in $59(73 \%)$ cases and of 23 pillion riders, 16 (69.5\%) got fracture of skull. Conclusion: Male riders of motorcycles belonging to age range 21-40 years were more prone to fatal injuries i.e., fractures of skull, neck, spine \& Abdomino-thoracic injuries. Abrasions, contusions and lacerations were the most common type of injuries. Helmet legislation needs to be supported by strong enforcement and social marketing campaigns. Reducing the incidence by strict implementation of traffic rules and safety education via electronic \& print media is need of the day.

Keywords: Two-wheeler, Fatalities, Frequency, Injury pattern, Motorbike accidents, Pillion rider.

\section{INTRODUCTION}

Road Traffic injuries \& deaths remain a serious public health problem globally and current trends suggest that this will continue to be the case in predictable future.1,2 Frightening increase in deaths and disabilities resulting from road traffic accidents during past few decades is matter of great concern all over the world representing eighth leading cause of death that claim more than 1.35 million lives each year and causing about 50 million injuries leading to disabilities. ${ }^{3}$ The death toll resulting from road traffic injuries is higher than those caused by HIV, tuberculosis and diarrheal diseases. ${ }^{4}$ Road traffic casualties involve individuals from all spheres of life without discrimination of age, gender, race or caste. 
Reportedly, more than $90 \%$ of all road accident fatalities occur in the low and middle income countries and inhabitants bear the greatest burden of road traffic fatalities and injuries which is disproportionately high in relation to the population \& number of motor vehicle in such countries. ${ }^{5}$ Citizens of low \& middle income countries have to face socio- economic burden as a result of death / disability and cost of long-term health care. ${ }^{6,7}$ Financial condition of poor families becomes worse due to increased living cost of the injured \& disabled members of their family. According to the researchers, the death toll of road accidents is decreasing in developed countries while the rate of mortalities is steadily rising in lowincome countries. ${ }^{8,9}$ More than half of all road traffic fatalities in the world are among vulnerable road users including pedestrians, motorcyclists and cyclists whereas; only motorcyclists comprise of one fourth of the death toll. ${ }^{10,11}$ According to report submitted by (WHO) in 2009; the death toll due to RTA was 25.3 deaths per 100,000 in Pakistan. ${ }^{12}$ A recent survey conducted by Pakistan Motorway (2019) reported that almost 1500016000 causalities occur annually in road traffic accidents which are very high in comparison to road traffic fatalities in rest of the world. In Pakistan, the actual number of fatalities due to RTAs is much higher as these are underreported that impedes the steps to be taken for road safety in order to reduce the road traffic fatalities. ${ }^{13}$

Cities of Pakistan are thickly populated, being industrial, overcrowded by motorized two wheelers, cyclists, animal carts, loader rickshaw and pedestrians on the same roads used by the heavy transport vehicles; hence more chances of road traffic accidents \& involvement of motorcyclists. Similar trend with higher number of road traffic fatalities has been documented by Sulehri et all4 in a local study on road traffic accident fatalities.

In Pakistan, one-wheeling is observed with great concern in youngsters presenting life threatening tricks such as lying on the motorcycles while driving, lifting up the front wheel and sometimes standing upright on the seats of a fast-moving motorcycle. ${ }^{15,16}$ According to the report of Rescue 1122 regarding traffic crashes in south Punjab, total 106,789 road accidents occurred from 2004 to 2017 in Multan. ${ }^{17}$ At least 70 motorcyclists were killed and 10,000 others sustained injuries of different nature during the first six months of the year 2018, which is 82.61 per cent of the total road crashes in Multan. According to Punjab Emergency Service; road accidents contribute major number of injuries i.e., $72 \%$ of total. ${ }^{18}$

Majority of motorcyclists involved in road traffic accidents are young adult males belonging to age range of 21-40 years. The male dominance with similar age groups dying most commonly because of head injuries; have been documented in many other studies. ${ }^{19-23}$

An attempt has been made in this study to find out the pattern \& severity of injuries with special reference to the body parts affected in motorized two wheelers accidents.

\section{METHODOLOGY}

Study Design: Cross-sectional Study.

Settings: Department of Forensic Medicine at Nishtar Medical University, Multan Pakistan.

Duration: One year from $1^{\text {st }}$ January, 2018 to $31^{\text {st }}$ December, 2018.

Sample Technique: Non-probability sampling.

Sample Size: 104

Inclusion Criteria: Only those died of motorized twowheeler accidents (riders \& pillion riders) were included. Exclusion Criteria: Those died of (RTAs) in four-wheeler and other than motorized two-wheeler were excluded.

Data Collection Procedure: Total 167 cases of road traffic fatalities brought for medicolegal autopsy and of those, 104 cases reported to be died in fatal two-wheeler accidents involving both; riders and pillion riders. The data regarding victim's age, gender, rider or pillion rider, frequency \& areas of injuries etc. were recorded after a thorough perusal of the hospital records and autopsy registers. Police inquest also examined when required. The postmortem examinations conducted to find out the site, frequency, severity \& extent of injuries while pattern / distribution of injuries and skull fractures observed to know the extent of head injury in each case. Data were analyzed using SPSS 20.

\section{RESULTS}

Total 167 cases of road traffic accidents brought for autopsy and of those; 104 reported to be died in twowheeler accidents involving 99 (95.20\%) males \& 5 $(4.80 \%)$ female consisting of $(78 \%)$ riders and $(22 \%)$ pillion riders. The most commonly affected age group was between 21-30 years involving $44(42.3 \%)$ cases followed by 31-40 years of age affecting 23 (22.2\%) victims. Fifteen $(14.4 \%)$ cases belonged to the age groups of 11-20 \& 41-50 years each whereas extreme ages of 0-10 \& 51-60 years contributed only $3(2.9 \%)$ and $4(3.38 \%)$ cases. However, majority 67 (64.5\%) victims belonged to the age range 21- 40 years. Distribution of age \& gender among victims of fatal two-wheeler accidents is shown in table 1.

Table 1: Age \& gender in two-wheeler accident fatalities ( $\mathrm{n}=104)$

\begin{tabular}{|l|c|c|c|c|}
\hline \multicolumn{1}{|c|}{ Age Group } & Male & Female & Total & Percentage \\
\hline $\mathbf{0 - 1 0}$ & 2 & 1 & 3 & $2.9 \%$ \\
\hline $\mathbf{1 1}-\mathbf{2 0}$ & 15 & 0 & 15 & $14.4 \%$ \\
\hline $\mathbf{2 1 - 3 0}$ & 41 & 3 & 44 & $42.3 \%$ \\
\hline $\mathbf{3 1 - 4 0}$ & 23 & 0 & 23 & $22.2 \%$ \\
\hline $\mathbf{4 1 - 5 0}$ & 15 & 0 & 15 & $14.4 \%$ \\
\hline $\mathbf{5 1 - 6 0}$ & 3 & 1 & 4 & $3.8 \%$ \\
\hline Total & $\mathbf{9 9}$ & $\mathbf{5}$ & $\mathbf{1 0 4}$ & $\mathbf{1 0 0} \%$ \\
\hline
\end{tabular}


As regard distribution of injuries; maximum 84 (80.8\%) were found on Head/Face followed by 42 (40.4\%) on lower limbs, $30(28.8 \%)$ on upper limbs and chest was injured in $26(25 \%)$ cases while injuries on pelvis found in $14(13.4 \%)$ cases, abdomen 8 (7.6\%) whereas, neck/spine involved in $12(11.5 \%)$ cases as shown in table 2.

Table 2: Site \& frequency of injuries

\begin{tabular}{|l|c|c|}
\hline \multicolumn{1}{|c|}{ Site of injury } & Frequency & Percentage \\
\hline Head / Face & 84 & $80.8 \%$ \\
\hline Neck / Spine & 12 & $11.5 \%$ \\
\hline Thorax & 26 & $25 \%$ \\
\hline Abdomen & 8 & $7.6 \%$ \\
\hline Pelvis & 14 & $13.4 \%$ \\
\hline Upper limbs & 30 & $28.8 \%$ \\
\hline Lower limbs & 42 & $40.4 \%$ \\
\hline
\end{tabular}

The patterns of injuries include fractures in 56(36\%) cases, abrasions in $48(31 \%)$, lacerations $38(24 \%)$ and contusions $14(9 \%)$ victims which are as shown below. table 3

Table 3: Pattern \& frequency of injuries

\begin{tabular}{|l|c|c|}
\hline \multicolumn{1}{|c|}{ Pattern of injury } & Frequency & Percentage \\
\hline Fractures & 56 & $36 \%$ \\
\hline Abrasions & 48 & $31 \%$ \\
\hline Lacerations & 38 & $24 \%$ \\
\hline Contusions & 14 & $9 \%$ \\
\hline
\end{tabular}

Out of 104 cases, majority 75 (72.11\%) cases died due to injuries over-head followed by $10(9.61 \%)$ involving thoracic region while abdomen \& pelvic injuries found in $10(9.61 \%)$ cases whereas; cervical injuries constitute 6 $(5.77 \%)$ and injuries over limbs observed in $3(2.90 \%)$ cases. Fracture of skull with brain injury was the most common cause of death in our study. table 4

Table 4: Frequency of fatal injuries \& parts of body involved $(n=104)$

\begin{tabular}{|l|c|c|}
\hline \multicolumn{1}{|c|}{ Site of injury } & Frequency & Percentage \\
\hline Head injury / Fracture Skull & 75 & $72.11 \%$ \\
\hline Cervical Spine injury & 6 & $5.77 \%$ \\
\hline Thorax/Chest & 10 & $9.61 \%$ \\
\hline Abdomino Pelvic & 10 & $9.61 \%$ \\
\hline Limb Fracture & 3 & $2.90 \%$ \\
\hline
\end{tabular}

Among 104 victims of fatal two-wheeler accidents; 81 $(78 \%)$ were riders \& $23(22 \%)$ pillion riders. Skull fracture was found in 59 out of 81 riders \&16 out of 23 pillion riders.
Figure 1: Distribution of skull fractures in riders

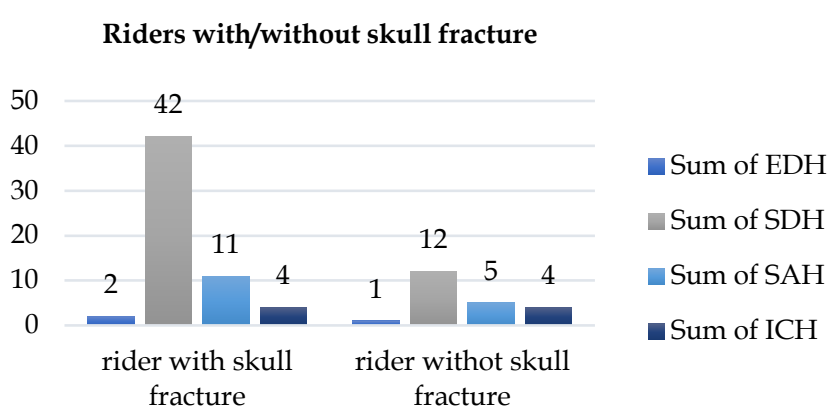

Figure 2: Distribution of skull fractures in Pillion riders

Pillion rider with / without skull fracture

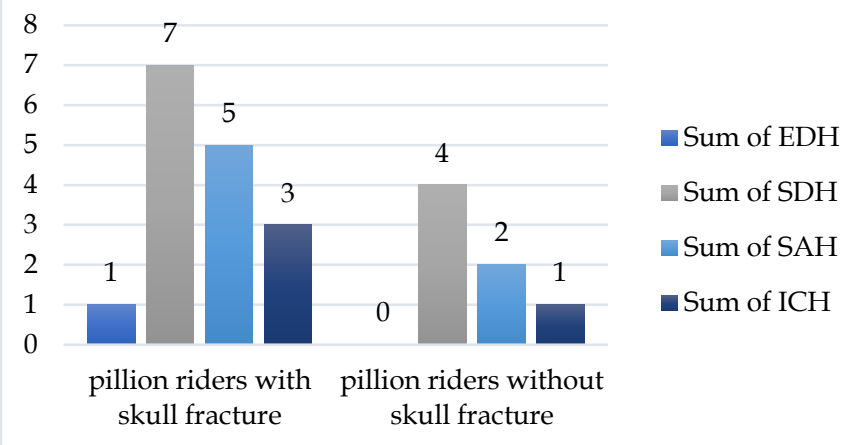

Sub-dural hemorrhage (SDH) was found in $71 \%$ cases followed by sub-arachnoid hemorrhage (SAH) 19\%, Intra cranial hemorrhage $(\mathrm{ICH}) \quad 7 \%$ and Extra Dural Hemorrhage $(\mathrm{EDH})$ in 3\% riders. While in pillion riders, SDH $44 \%$, followed by SAH in 31\%, ICH in $19 \%$ and least is $\mathrm{EDH}$ in $6 \%$ cases where skull was fractured. $\mathrm{EDH}, \mathrm{SDH}$ \& SAH in relation to skull without fracture were found as $\mathrm{SDH}$ in $55 \%$ cases followed by SAH in $22 \%$, ICH in $18 \%$ and least is $\mathrm{EDH}$ in $5 \%$ riders, $\mathrm{SDH}$ in $57 \%$, followed by $\mathrm{SAH}$ in $29 \%$, ICH in $14 \%$ and $\mathrm{EDH}$ in $0 \%$ in pillion riders.

\section{DISCUSSION}

Road traffic accidents are considered to be a problem of developing countries and $90 \%$ of deaths due to (RTAs) occur in low or middle incomes countries. ${ }^{5}$ Although use of motorcycle is easier being less expensive, covers more distance in overcrowded roads but there is great threatening compared to car because rider's body parts are unprotected \& eventually, motorcyclists often sustain severe injuries in multiple anatomic regions leading to death or disability of the riders.

According to the National Highway Traffic Safety Administration (NHTSA), the motorcycle riders were twenty-seven times more likely to die in a crash than occupants of a car per vehicle distance travelled. ${ }^{24}$ Some of the cities of Pakistan are excellently developed while others still in process of urbanization. The increasing number of motor vehicle has shown a rise in the 
development of low \& middle income countries but also chances of road traffic accidents also increased leading to death and disabilities. ${ }^{25}$

Of the total 104 victims of fatal motorcycle accidents, majority were males accounting for $95.20 \%$ of the cases as compared to $4.80 \%$ females. This pattern of male predominance has been observed in other studies 19-23. Most commonly males are exposed to the roads regarding their duties, business and earnings for whole family. The predominance of male in road traffic fatalities was also reported in a study by Pate et al, ${ }^{26}$ indicating male to female ratio as 2.05:1 whereas similar results have also been documented by several studies. ${ }^{27-31}$

In our study, $64.5 \%$ of fatal road accidents cases belonged to the age group 21-40 years. Our results are in accordance with a study conducted by Arif et al 19 reporting the involvement of $46.55 \%$ cases of the similar age range 21-40 years while the death toll belonging to same age group in our study was bit higher $64.5 \%$ cases. In our study, fatal injuries were observed on the head in $72.11 \%$ cases while Arif et al ${ }^{19}$ reported the presence of fatal head injuries in $66.37 \%$ victims of road traffic accidents which is almost in line with our finding. Another study by Masud et al ${ }^{20}$ reported the presence of fatal injuries on the heads of $53.5 \%$ cases and $38.4 \%$ victims belonging to 3 rd \& 4 th decades of life while $86 \%$ of the victims were males; almost all results supporting the finding of our study. Involvement of majority males, died due to head injuries and $35.5 \%$ cases belonging to 3rd decade of life being victims of unnatural deaths has also been documented by Ummara et al ${ }^{21}$ in a study of 138 unnatural deaths in tertiary care hospital of southern Punjab. Finding of this study are in line with Singh et al 22 while discussing the issues and challenges of road traffic accidents. Our results are consistent with some other studies $23,24,26,31$ showing that majority of the cases died in fatal motorcycle accidents belonged to the age group 2140 years. The reason for involvement of this young and active age group being victims of road accidents is; because they are the earning members of their family and most of the times have to move on roads especially those with 21-30 years of age were probably more affected as many of those being students having reckless and adventurous in driving, leading to accidental fatalities as well as disabilities. The youngster's are fond of riding unsafe and high-velocity motorcycles for traveling but responsible for increased number of death \& disabilities in this age group. ${ }^{32}$

Injuries over head \& face were observed on $84(80.8 \%)$ cases, lower extremities in $42(40.4 \%)$, while upper limbs affected in $30(28.8 \%)$ and thorax was found injured in $26(25 \%)$ cases of fatal road crashes. As reported by a researcher Sadeghi-Bazargani $\mathrm{H}$ et $a^{33}$ while examining 1840 fatalities due to motorcycle accidents; $87.5 \%$ fatal injuries were observed over the areas of head / cervical spines \& face of the victims while chest \& abdomen got injured in $23.9 \%$ cases.

The authors of this study observed majority of injuries overhead / face being cause of death. The injuries sustained by the victims of motorized two-wheeler crash occur due to being dragged on the road and at times run over injuries may also be caused by other fast-moving vehicles.

\section{CONCLUSION}

Male riders of motorcycles belonging to age range 21-40 years were more prone to fatal injuries i.e., fractures of skull, neck, spine \& Abdomino-thoracic injuries. The major roots behind bikers' accidents include onewheeling, over-speeding, reckless driving without using helmets. As motorized two wheelers constitute a large portion of the vehicle fleet in southern Punjab. The exponentially increasing number of automobile vehicles, poor adherence to traffic rules, lack of maintaining lane discipline, driving in zigzag patterns, poorly maintained and overcrowded roads, and lack of awareness about use of helmets are altogether responsible for accidents.

\section{LIMITATIONS}

The study was conducted in one Centre only on smaller data available in that institution. Further multicentered prospective studies could be conducted to ascertain accurate results regarding motorized two-wheeler accident fatalities.

\section{SUGGESTIONS / RECOMMENDATIONS}

Helmet legislation needs to be supported by strong enforcement and social campaigns. Reducing the incidence by strict implementation of traffic rules and safety education via electronic \& print media is need of the day. Driving license should only be issued after suitable training \& tests of the applicants.

\section{CONFLICT OF INTEREST / DISCLOSURE}

No conflict of interest exists among authors of this study, as the same was approved from ethical review committee.

\section{ACKNOWLEDGEMENTS}

I acknowledge my worthy teacher Prof. Dr. Pervaiz Zarif, Head of Forensic Medicine Department, Ameer ud Din Medical College, Lahore of for the guidance \& support. I am also thankful to Junaid Altaf Qasim, student of $4^{\text {th }}$ year MBBS at Aziz Fatimah Medical \& Dental College Faisalabad, sparing valuable time for critical proof reading of this article.

\section{REFERENCES}

1. World Health Organization. Projections of mortality and causes of death, 2015 and 2030. World Health Organization; 2013. Available from: http:/ / www.who.int/healthinfo/ global_burden_disease/projections2015_2030/en/ 
2. Foreman KJ, Marquez N, Dolgert A, Fukutaki K, Mcgaughey M, Pletcher MA, et al. Forecasting life expectancy, years of life lost, allcause and cause-specific mortality for 250 causes of death: reference and alternative scenarios 2016-2040 for 195 countries and territories. Lancet. 2018;392(10159):2052-90.

3. Global status report on road safety 2018: Summary. Geneva: World Health Organization; 2018 (WHO/NMH/NVI/18.20).

4. World Health Organization. Global Health Estimates. World Health Organization; $2018 . \quad$ Available: http://www.who.int/healthinfo/global_burden_disease/en/

5. World Health Organization. WHO: Road traffic injuries? Fact sheet No358. September 2011. Available from URL: http://www.who.int/mediacentre/factsheets/ fs358/en/index.html.

6. Heydari S, Hoseinzadeh A, Ghaffarpasand F, Hedjazi A, Zarenezhad M, Moafian et al. Epidemiological characteristics of fatal traffic accidents in Fars's province, Iran: A community-based survey. Public Health. 2013;127(8):704-9.

7. Pathak S, Jindal A, Verma A, Mahen A. An epidemiological study of road traffic accident cases admitted in a tertiary care hospital. Med J Armed Forces India. 2014;70(1):32-5.

8. WHO. Pedestrian Safety: A Road Safety Manual for DecisionMakers and Practitioners; WHO: Geneva, Switzerland, 2013.

9. Pan RH, Chang NT, Chu D, Hsu KF, Hsu YN, Hsu JC, et al. "Epidemiology of orthopedic fractures and other injuries among inpatients admitted due to traffic accidents: A 10-year nationwide survey in Taiwan". The Scienti World J. 2014;5:(637872).

10. Araujo M, Illanes E, Chapman E, Rodrigues E. Effectiveness of interventions to prevent motorcycle injuries: systematic review of the literature. Int J Inj Contr Saf Promot. 2017;24(3):406-22.

11. Abedi L, Sadeghi-Bazargani H. Epidemiological patterns and risk factors of motorcycle injuries in Iran and Eastern Mediterranean Region countries: a systematic review. Int J Inj Contr Saf Promot. 2017;24(2):263-70.

12. World Health Organization. Global status report on road safety: Time for action. Available from URL: http://whqlibdoc.who.int/publications/2009/9789241563840_en g. pdf.

13. Mirza FH, Hassan Q, Jajja N. An autopsy-based study of death due to road traffic accidents in metropolis of Karachi. JPMA. 2013;63(2):156-60.

14. Sulehri MA, Qasim AP. Road Traffic Accidents Fatalities in Faisalabad. Professional Med J. 2012;19(2):180-6.

15. https://www.researchgate.net/publication/307618219_667_Mot orcycle_one-wheeling a fatal venture in Pakistan.
16. Tahir MN, Akbar AH, Kayani A, et al. 667 Motorcycle onewheeling: a fatal venture in Pakistan. Injury Prevention. 2016;22(2):239-40.

17. Rescue 1122 report: South Punjab witnesses over 550,000 road accidents in 13 years. Owais Qarni Published: 8th Jan, 2018.

18. Rescue 1122 responding to 1,004 road accidents in Punjab everyday Report September 5, 2018.

19. Arif M, Ahmed M, Rasool SH. Road traffic accidents; autopsybased study in Multan. Professional Med J. 2015;22(5):621-6.

20. Masud U, Shehzad MA, Saeed A. Epidemiology of fatalities in road traffic accidents in Faisalabad during 2008-2009-an autopsy-based study. APMC. 2011;5(1):39-42.

21. Munir U, Naeem T, Abaid T, Qasim AP, Anjum H, Abbas Q. Demographic Profile of Unnatural Deaths; Autopsy Study at Tertiary Care Hospital of Southern Punjab. APMC 2019;13(1):60-3.

22. Singh SK. Road Traffic Accidents in India: Issues \& Challenges. Transportation Research Procedia. 2017;25:4708-19.

23. Hesse CA, Ofosu JB. Epidemiology of road traffic accidents in Ghana. Euro Sci J. 2014;10(9):370-81.

24. National Highway Traffic Safety Administration (NHTSA). Facts+Statistics: Motorcycle crashes.2017. Available from: https://www.iii.org/fact-statistic/facts-statistics-motorcyclecrashes\#2008-2017

25. Ravi BK, Goel N, Kumar B, Prasad CS, Chouhdary AK. Pattern of injuries in Road Traffic Accidents in Ranchi, Jharkhand: An Autopsy Based Study. Int J Med Res Prof. 2017;3(5):115-7.

26. Pate RS, Hire RC, Rojekar MV. Pattern of head injury in central India population. Int J Res Med Sci. 2017;5(2):3515-9.

27. Thube HR, Pawale DA, Jagtap NS. Study of Pattern of fatal head injury Kolhapur region. J Forensic Med Sci Law.2015;24(2):11-5.

28. Patil A, Vaz W. Pattern of Fatal Blunt Head Injury: A Two-Year Retrospective / Prospective Medico Legal Autopsy Study. J Indian Acade Forensic Med. 2010;32(2):144 -9.

29. Kumar L, Agarwal S, Singh T, Garg R. Patterns of head injury at tertiary care hospital. Int J Scientific Study. 2014;1(5):5-8.

30. Shivkumar B, Srivastava P, Shantakumar P. Pattern of Head Injuries in Mortality due to Road Traffic Accidents involving TwoWheelers. J. Indian Acad. Forensic Med. 2010; 32(3):239-42.

31. Hasini Chandra BR. Death Due to Road Traffic Accidents: A Forensic Study. Indian J Forensic Med Pathol. 2019;12(2):67-71.

32. Rolison JJ, Hewson PJ, Hellier E, Hurst L. Risks of high-powered motorcycles among younger adults. Am J Public Health. 2013;103(3):568-71.

33. Sadeghi-Bazargani H, Samadirad B, Hosseinpour-Feizi H. Epidemiology of Traffic Fatalities among Motorcycle Users in East Azerbaijan, Iran. Biomed Res Int. 2018;2018:6971904. 